\title{
A NOÇÃO DE PROBLEMA NOS ESTUDOS DA TRADUÇÃO: UM NOVO OLHAR TEÓRICO COM EXEMPLOS DO PAR LINGUÍSTICO ESPANHOL/PORTUGUÊS
}

\author{
THE NOTION OF PROBLEM IN TRANSLATION STUDIES: A NEW \\ THEORETICAL LOOK WITH EXAMPLES IN SPANISH/PORTUGUESE \\ TRANSLATION
}

\author{
LA NOCIÓN DE PROBLEMA EN LOS ESTUDIOS DE TRADUCCIÓN: UNA \\ NUEVA MIRADA TEÓRICA CON EJEMPLOS DE LA TRADUCCIÓN ESPAÑOL/ \\ PORTUGUÉS
}

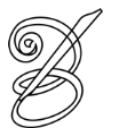 \\ Marina Leivas WAQUIL* \\ Universidade Federal do Rio Grande do Sul, Brasil
}

\begin{abstract}
Resumo: Este trabalho deriva da proposta de tradução do espanhol para o português de uma das obras mais fundamentais da área dos Estudos da Tradução, Traducción y Traductología: Introducción a la Traductología (2013), da tradutora, professora e autora espanhola Amparo Hurtado Albir, que retoma as principais definições, características e as noções de análise da tradução a partir dos mais diferentes teóricos e de suas perspectivas. Segundo Franco (2010), essa é a 21 a obra mais citada nos estudos sobre a tradução, sendo a única publicação editada no século XXI e, além disso, a única em língua espanhola entre as cinquenta mais referenciadas. A partir dessa tradução, e prevendo a complexidade do processo tradutório a ser enfrentado, propôs-se uma análise teórica e empírica sobre uma das noções mais centrais e, ao mesmo tempo, menos refletidas nos Estudos da Tradução, a de problema. Para isso, revisitou-se a noção de problema de modo geral, recorrendo a discussões matemáticofilosóficas, que têm sua origem em Platão e que se desenvolveram com o aporte de filósofos contemporâneos, como Henri Bergson e Gilles Deleuze. Além disso, apesar da carência de estudos, também foi realizada uma pesquisa bibliográfica na literatura da área da tradução por meio da retomada de três teóricos que se dedicaram ao estudo dessa noção - Mounin (1963), Lörsher (1991), Nord (1997) e o Grupo PACTE e Hurtado Albir (2011; 2013) - , analisando suas reflexões e as categorizações propostas por esses autores. A partir de um estudo exploratório em que se realizou a tradução do primeiro capítulo de Traducción y Traductología, foram identificados, compilados e analisados quantitativa e qualitativamente os problemas encontrados, constatando a frequência expressiva de problemas terminológicos. Com base nisso, propôs-se uma nova classificação de problemas de tradução, incluindo essa categoria específica. Como conclusão de destaque desta pesquisa, está a proposta de uma concepção sobre a noção de problema que o entenda de modo positivo, como propositor de novos conhecimentos e perspectivas para as mais diversas áreas do saber.
\end{abstract}

Palavras-chave: Tradução. Espanhol. Português. Terminologia. Problema.

\begin{abstract}
This work derives from the proposal of translation from Spanish to Portuguese of one of the most fundamental works in the area of Translation Studies, Traducción y Traductología: Introducción a la Traductología, of the Spanish translator, teacher and author Amparo Hurtado Albir, which takes up the main definitions, characteristics and notions of translation analysis from the most different theorists and their perspectives. According to Franco (2010), this is the 21st most cited work in translation studies, being the only publication published in the 21st century and, moreover, the only one in the Spanish language among the fifty most referenced ones. From this translation, and foreseeing the complexity of the translation process to be faced, we proposed to study theoretically and empirically one of the most central and at the same time less reflected in
\end{abstract}


the Translation Studies: translation problems. For this, we revisit the notion of problem in general, resorting to mathematical-philosophical discussions, which have their origin in Plato and that have developed with the contribution of contemporary philosophers such as Henri Bergson and Gilles Deleuze. In addition, despite the lack of studies, we also carried out a bibliographical research in the translation literature, taking up three theorists who studied the notion, Mounin (1963), Lörsher (1991), Nord (1997) and the PACTE Group and Hurtado Albir (2011; 2013), analyzing their reflections and the categorizations proposed by these authors. From an exploratory study in which we translated the first chapter of Traducción y Traductología: Introducción a la Traductología, we identified and analyzed quantitatively and qualitatively the problems encountered, noting the expressive frequency of terminological problems. Based on this, we have proposed a new classification of translation problems, including that specific category. As a conclusion to highlight this research is the proposal of a conception about the notion of problem that understands it in a positive way, as a proposer of new knowledge and perspectives for the most diverse areas of knowledge.

Keywords: Translation. Spanish. Portuguese. Terminology. Problem.

Resumen: Este trabajo es resultado de la propuesta de traducción del español al portugués de una de las obras más fundamentales en los campos de los de estudios de Traducción, Traducción y Traductología: Introducción a la Traductología (2013), de la traductora, profesora y autora española Amparo Hurtado Albir, que recoge las principales definiciones, características y temas de análisis de la traducción de los más diferentes teóricos y sus perspectivas. Según Franco (2010), la obra de Hurtado Albir es el trabajo número 21 más citada em los estudios de traducción, es la única publicada en el siglo XXI y, además, la única en el idioma español entre las cincuenta más referenciadas. Con la realización de esta traducción y considerando la complejidad de este proceso, se propuso un análisis teórico y empírico sobre una de las nociones más centrales y, a la vez, menos discutidas en los estudios de traducción, la de problema. Para ello, se revisó la noción de problema en general, recurriendo a discusiones matemático-filosóficas, que tienen su origen en Platón y que se desarrollaron con la contribución de filósofos contemporáneos, como Henri Bergson y Gilles Deleuze. Además, pese a la falta de estudios, también se realizó una investigación bibliográfica en la literatura en el área de la traducción con la reanudación de tres teóricos que se dedicaron al estudio de esta noción: Mounin (1963), Lörsher (1991), Nord (1997), el Grupo PACTE y Hurtado Albir (2011; 2013), analizando sus reflexiones y categorizaciones. Con un estudio exploratorio en el que se llevó a cabo la traducción del primer capítulo de Traducción y Traductología, los problemas encontrados se identificaron, compilaron y analizaron cuantitativa y cualitativamente, mostrando la frecuencia expresiva de los problemas terminológicos. Sobre esta base, se propuso una nueva clasificación de los problemas de traducción, incluyendo esa categoría específica. Como conclusión principal de esta investigación, se encuentra la propuesta de una concepción sobre la noción de problema que la entiende de manera positiva, como un proponente de nuevos conocimientos y perspectivas para las áreas más diversas del conocimiento.

Palabras clave: Traducción. Español. Portugués. Terminología. Problema.

RECEBIDO EM: 18/02/2019

ACEITO EM: 20/08/2019

PUBLICADO EM: 10/2019

WAQUIL, Marina Leivas. A noção de problema nos Estudos da Tradução: um novo olhar teórico com exemplos do par linguístico espanhol/português. Belas Infiéis, Brasília, v. 8, n. 4, p. 13-34, 2019. 


\section{Introdução}

$\mathrm{U}$

m dos principais escritores do século XX e muito conhecido, também como um grande teórico da tradução, Humberto Eco (2007) já constatava uma expansão da tradução como objeto de teorização e, consequentemente, dos estudos da tradução. Destacando a proliferação de grupos de pesquisa, de cursos e departamentos especializados na área e na formação de tradutores, o escritor, teórico e tradutor italiano apontava como razões e impulso para esse desenvolvimento da área fatores como: 1) a expansão do fenômeno da globalização, que aproxima cada vez mais os diversos grupos sociais, suas culturas e línguas; 2) um aumento do interesse pelos estudos semióticos, nos quais se insere, inevitavelmente, a tradução a partir da análise e da reflexão sobre, por exemplo, significados de enunciados; 3) e, claro, a expansão informática (além de digital e on-line, acrescentamos), que é um motor intenso para o interesse e a necessidade de discussões sobre ferramentas e insumos para o processo tradutório e que, como resultado, vem apurando, segundo o autor, os modelos de tradução automática.

Nesse contexto, em 2017, apresentou-se uma tese de doutoramento que, com o objetivo de introduzir a tradução inédita para o português da obra Traducción y Traductología: Introducción a la Traductología (em sua última versão, de 2013), da autora, tradutora e professora espanhola Amparo Hurtado Albir, refletiu e discutiu sobre uma das noções mais carentes de análise teórica e, principalmente, empírica nos estudos da tradução: a de problema.

Para isso, cabe destacar, antes de mais nada, a importância de Traducción y Traductología: Introducción a la Traductología nos estudos contemporâneos da tradução. Reconhecida internacionalmente, a obra de Hurtado Albir apresenta um percurso histórico a respeito da tradução, sua definição, sua evolução, seu desenvolvimento como disciplina, as teorias propostas e as noções que engloba. A autora desenvolve sua reflexão não só de seu próprio ponto de vista, mas das visões e propostas de inúmeros teóricos da área. Além disso, é clara a sua enorme relevância no contexto do ensino de tradução em universidades, já que essa obra é recorrente na bibliografia dos cursos de bacharelado e de pós-graduação em Estudos da Tradução cujos objetivos são formar e aperfeiçoar tradutores, respectivamente. Para ilustrar isso, cabe mencionar o estudo de Franco (2010), que analisa a base de dados de referências bibliográficas da área da Tradução e da Interpretação (BITRA) ${ }^{1}$, demonstrando o alcance e a importância do livro de Hurtado Albir. No artigo Who's who and what's what in Translation Studies (FRANCO, 2010), o autor apresenta uma lista com as 51 obras mais citadas nos estudos sobre tradução. Traducción y Traductología: Introducción a la Traductología figura na $21^{\mathrm{a}}$ 
posição, sendo a única publicação editada no século XXI e, ademais, a única em língua espanhola que consta na relação apresentada.

Assim, com essa tradução, embasada em reflexão teórica, buscou-se contribuir para os estudos que tomam como foco a tradução entre o espanhol e o português de maneira geral. Mais especificamente, objetivou-se produzir uma reflexão sobre e oferecer subsídios para a pesquisa em tradução de textos em linguagem especializada, que, no caso dessa pesquisa, tomando a obra de Hurtado Albir como texto a ser traduzido, tratava-se da linguagem da área dos Estudos da Tradução (Traductología).

A partir disso, neste artigo, pretende-se apresentar um recorte do estudo exploratório realizado em Waquil (2017) - etapa fundamental para a realização da pesquisa — para, da mesma forma, oferecer uma contribuição aos estudos e pesquisas que têm como foco a tradução entre os idiomas espanhol e português. Para tal, retoma-se uma noção central para a área a partir de uma reflexão teórica e de uma análise resultado da atividade prática de traduzir, apresentando problemas constatados na tradução de uma das obras mais importantes já publicadas nos Estudos da Tradução. Dessa forma, primeiramente, será apresentada uma discussão teórica

16 sobre a noção de problema, seguida por sua contextualização nos Estudos da Tradução e, então, pela apresentação de uma análise empírica de problemas constatados na tradução do espanhol para o português da obra Traducción y Traductología: Introducción a la Traductología (HURTADO ALBIR, 2013).

\section{A noção de problema}

Antes de adentrar na discussão sobre problemas de tradução, é importante esclarecer a noção de problema de modo geral, que é extremamente antiga e tem um alcance destacadamente amplo - afinal, todos sabemos o que é um problema, lidamos com eles todos os dias e nos mais variados contextos. Assim, considera-se pertinente, antes de analisá-la sob a perspectiva da Tradutologia, apresentar uma reflexão sobre a noção em um espectro mais basilar, que permite entendê-la em sua fundamentação e extensão para, então, passar às especificidades do problema analisado em contexto de tradução.

Menções à identificação e à solução (ou não) de "problemas" podem ser encontradas nas mais diversas áreas de estudo: passando pelas humanas, como a Psicologia e sua discussão sobre problemas psicológicos, até áreas que tratam de problemas a partir de sua resolução com algoritmos, como a Ciência da Computação e a Inteligência Artificial. Segundo o Houaiss (2001), problema, que deriva do latim problematis e do grego problematos, é “o que se tem 
diante de si; obstáculo; questão". Entre as acepções que esse dicionário, uma das principais obras lexicográficas do Brasil, apresenta para a entrada "problema", pode-se identificar traços distintivos extremamente sutis e pouco esclarecedores: "assunto controverso, que pode ser objeto de pesquisas científicas ou discussões acadêmicas"; "questão social que traz transtornos e que exige grande esforço e determinação para ser solucionado"; "situação difícil; conflito emocional", entre outras. Há referência à entrada em contexto de apenas uma área específica do conhecimento, a Matemática, na última acepção: "MAT tarefa de calcular uma ou várias quantidades desconhecidas" (HOUAISS, 2011). Não é por acaso que, na Matemática, a ideia de problema é fundamental e, nesse contexto, assume a forma de uma questão que é proposta em linguagem matemática e para a qual é possível identificar uma solução, várias soluções ou nenhuma solução.

No entanto, historicamente, foi na confluência da Matemática com outra área que surgiram as mais substanciais discussões sobre problema: a Filosofia, na qual as discussões sobre problemas, além de muito antigas, são prolíficas e ofereceram bases para a sua reflexão. A interação da reflexão matemática com a filosófica encontra-se expressivamente na figura de Platão, filósofo e matemático da Grécia Antiga, e nas obras que compilam suas reflexões, nas quais encontramos o fio condutor para as discussões na esfera da noção de "problema".

Roque (2008), por exemplo, estuda o problema matemático a partir da proposta de “mundo inteligível” de Platão (A República, Livro VI), em que estão: 1) as ciências hipotéticas, que oferecem os primeiros princípios para a constituição de conhecimento científico, e 2) a dialética, que se baseia nas hipóteses para alcançar o não hipotético, por meio da razão, chegando às ideias. Aproximando os pressupostos platônicos da Matemática, Roque (2008) relaciona a Geometria com as ciências hipotéticas, que é, também, o principal exemplo utilizado por Platão e por muitos filósofos sucessores para a discussão da noção problema.

Assim, analisando os pressupostos platônicos, Roque (2008) conclui que, nessa linha de pensamento, o problema tem a sua validade e seu valor porque pode ser solucionado e, portanto, ascender ao mundo inteligível proposto por Platão. Assim, conforma novos princípios para as ciências, de forma que "o conjunto dos problemas decalca-se exatamente sobre o conjunto das soluções, entes eternos que preexistem ao próprio problema e são sua razão de ser" (ROQUE, 2008, p. 141).

Com base nessa reflexão, mas contrapondo-a, a autora propõe outra concepção de problema, considerando que o problema e sua solução são entidades de natureza diferente: o problema existe por si só, não sendo necessária uma solução para que ele se constitua como tal. 
A visão dada ao problema é, então, mais positiva, já que se passa a vê-lo como uma "criação, uma novidade, um vir-a-ser que traz à realidade algo que nunca existiu" e não mais como "uma falta que virá a ser preenchida pelo conhecimento da solução preexistente" (ROQUE, 2008, p. 141).

Assim, propondo a separação de duas noções tão comumente relacionadas (problema e solução), Roque (2008) se baseia na obra do filósofo Henri Bergson, que propõe como método filosófico a intuição, que, por sua vez, é formada por regras. É na primeira dessas regras que encontramos a discussão acerca dos problemas, destacada na análise de outro ilustre filósofo, Gilles Deleuze (2012, p. 11): “aplicar a prova do verdadeiro e do falso aos próprios problemas, denunciar os falsos problemas, reconciliar verdade e criação no nível dos problemas". No bergsonismo, é mais importante encontrar e colocar o problema do que propriamente resolvêlo; o problema recebe caráter essencial: a colocação e a resolução dos problemas, superando obstáculos, determinam a vida. Para Deleuze, da mesma forma, "a história dos homens, tanto do ponto de vista da teoria quanto da prática, é a da constituição de problemas" (DELEUZE, 2012, p. 12), de modo que a liberdade é conquistada a partir da consciência da importância 18 dessa atividade.

A partir dessa discussão filosófico-matemática, apurada e desenvolvida por Roque (2008) e das reflexões de Bergson e Deleuze, depreende-se, em Waquil (2017), que:

a) um verdadeiro problema pode permanecer sem solução;

b) um problema prescinde de solução;

c) um problema não se esgota ao ser solucionado;

d) um problema não supõe a ausência de conhecimento; pelo contrário, é a própria gênese do conhecimento.

Assim, nessa perspectiva, os problemas perdem a carga negativa (exposta, por exemplo, nas acepções apresentadas no Houaiss - controverso, obstáculo, difícil, distúrbio) — quando se constata a importância fundamental que eles têm na geração de conhecimento e na evolução das ciências. Sua proposição leva a novas suposições e teses, como exemplifica Roque (2008, p. 143), referindo-se ao campo da Matemática: “um dos exemplos mais simples do papel dos problemas em matemática é o fato de que ela evolui por conjecturas, e é justamente no processo de se demonstrar ou de se refutar uma conjectura que novas teorias são formuladas". 
Dessa maneira, considerando os pressupostos matemático-filosóficos, propõe-se uma visão de problema como elemento positivo no desenvolvimento de qualquer pesquisa científica.

\begin{abstract}
Enfim, é preciso garantir que o problema não desapareça, não seja uma motivação provisória, um negativo anterior ao saber, mas que insista e permaneça como um elemento genético do conhecimento, mantendo-se como força positiva no saber que se constituiu a partir dele. Apenas deste modo, as soluções deixarão de ser reproduzidas e poderão continuar a ser reinventadas (ROQUE, 2008, p. 145).
\end{abstract}

Defende-se, portanto, que a sua discussão é, para qualquer área do conhecimento humano, imprescindível: é imanente à sua solução, já que sua simples proposição é fonte produtora de novas e possíveis teorias.

\title{
1.1 A noção de problema nos Estudos da Tradução
}

Nos Estudos da Tradução, no entanto, embora tenha relevância central, a noção de problema ainda se encontra pouco aprofundada pelos teóricos da área, carecendo de discussão e exame detalhado, embora seja muito importante para o ensino e para a formação de tradutores. Segundo Hurtado Albir (2013), ainda não há consenso em relação a uma definição dessa noção e tampouco uma categorização completa dos tipos existentes.

Apesar disso, ao revisar a literatura da tradução, foram identificados e selecionados autores que, embora não se dediquem exclusivamente à discussão da noção de problema, apresentam alguma reflexão sobre a mesma em sua teorização. Assim, em Waquil (2017), foram encontrados subsídios na discussão de Mounin (1963), um dos pioneiros na discussão sobre o tema e que usa os subsídios da Linguística para analisar o fenômenos da tradução. Em Lörsher (1991), tomou-se a reflexão sobre os problemas de tradução a partir da análise da performance do tradutor e as suas estratégias. De Nord (1997), utilizou-se o estudo que, do ponto de vista da didática e também do profissional, propõe uma categorização de problemas. Finalmente, na pesquisa do Grupo PACTE ${ }^{2}$ (2011; 2013), coordenado por Hurtado Albir, serviu a discussão a partir do contexto da resolução de problemas como uma das características da competência tradutória.

Assim, inicialmente, na obra de Georges Mounin, Les Problèmes Théoriques de la Traduction (1963), fundamental na discussão sobre a noção de problema nos Estudos da Tradução, destaca-se que, embora o autor se baseie em um enfoque estritamente linguístico e, por isso, tenha um ponto de vista limitado — , encontra-se um estudo extremamente 
importante por ter sido um dos primeiros a contribuir para uma discussão que, embora décadas depois de seu trabalho, ainda se encontra pouco aprofundada.

Em sua reflexão, o autor apresenta a ideia de que a Linguística pode esclarecer os problemas de tradução e ajudar na sua compreensão. O próprio estudo da tradução é visto pelo teórico como uma ramificação da Linguística, e não como uma disciplina independente. Por outro lado, defende o desenvolvimento da tradução, sobre a qual lamenta que fosse, à época, "um setor inexplorado, inclusive ignorado [...], estando na intersecção entre diversas ciências" (MOUNIN, 1963, p. 10, tradução nossa ${ }^{3}$ ).

A partir disso, Mounin entende que a tradução é formada por aspectos extralinguísticos, mas destaca que, na base de toda operação de tradução, estão características de análise e procedimentos especificamente linguísticos. Então, partindo da ideia de que a Linguística como ciência pode ajudar a esclarecer o fenômeno da tradução, Mounin desenvolve sua obra. Desse modo, baseando-se na contribuição da Linguística, o autor foca sua análise nos problemas, concentrando-se na dicotomia da possibilidade/impossibilidade da tradução para analisá-los. Sua obra tem um enfoque declaradamente teórico sobre os problemas de tradução e não oferece uma categorização explícita. Além disso, detém-se a revisar linguistas e teóricos da tradução com enfoque linguístico e a refletir sobre os problemas derivados da grande pergunta do livro: a tradução é possível?

Em suas conclusões, Mounin reitera a resposta que oferece ao leitor ao longo de todo o livro: embora existam dificuldades e problemas que sugiram a ideia de que essa atividade é impossível, a tradução é, sim, possível. A partir da contribuição de teóricos e suas teorias linguísticas, o autor entende que as línguas representam formas específicas de ver o mundo e, consequentemente, de analisar a experiência que resulta dele. No entanto, admite que as línguas mudam menos que as experiências de mundo, não conseguindo acompanhar sua diacronia; as mudanças nas experiências, portanto, não se refletem automaticamente nas línguas. A tradução, nesse contexto, como um processo que se vale de línguas e seus mundos, tampouco é imóvel ou atemporal.

Com outro ponto de vista, Lörscher (1991) desenvolve uma abordagem empírica para realizar sua pesquisa, cujo interesse epistemológico principal é linguístico. Nesse estudo, o autor se dedica a analisar a performance de tradutores a partir de um corpus de traduções oralmente produzidas. Essa performance é situada dentro do processo (mental) de tradução, e o autor a analisa com o objetivo de identificar e recuperar as estratégias que os tradutores empregam. Assim, Lörscher (1991) busca oferecer uma análise tanto quantitativa quanto 
qualitativa, criticando modelos e estudos prescritivos, teóricos e especulativos. Seu intuito é oferecer um resultado descritivo, baseado em pesquisa empírica e concentrado em dados existentes.

Embora não seja o foco central, a noção de problema é discutida porque é a partir dela que o autor chega a uma de suas principais discussões. $O$ teórico alemão propõe que os tradutores empregam estratégias para resolver os problemas, configurando uma das características da performance dos sujeitos. Para Lörscher (1991, p. 201, tradução nossa ${ }^{4}$ ), a importância dos problemas de tradução se dá pelo fato de que eles "funcionam tanto como ponto de partida quanto são a razão para o uso de estratégias de tradução. Como consequência, as estratégias de tradução só ocorrem quando existem problemas de tradução".

Lörscher (1991) entende os problemas, então, como uma manifestação identificada em segmentos do texto da língua-fonte e os considera partes estratégicas da tradução. A categorização de problemas proposta pelo autor, no entanto, é restrita a aspectos estritamente linguísticos, como é possível observar pelos tipos de problema que apresenta:

a) Lexicais: lexemas individuais na língua-fonte que não têm lexemas correspondentes disponíveis na língua-alvo.

b) Sintáticos: estrutura sintática em um segmento do texto na língua-fonte que não tem uma estrutura correspondente disponível na língua-alvo.

c) Léxico-sintáticos: fenômeno tanto lexical quanto sintático, ou quando não é possível identificar de qual dos dois fenômenos se está tratando.

Para o autor, a partir de uma análise empírica de dados, o processo de tradução é composto por fases problemáticas e não problemáticas que se referem a segmentos do texto na língua-fonte. Nas fases problemáticas, o tradutor tem que lidar com obstáculos que "impedem ou atrasam, ou apenas permitem, parcial ou inadequadamente, a transformação de segmentos do texto da língua-fonte para a língua-alvo" (LÖRSCHER, 1991, p. 204, tradução nossa ${ }^{5}$ ) além disso, precisa aplicar uma abordagem de resolução de problemas. As fases não problemáticas ocorrem sempre que tradutor realiza sua performance de forma automatizada, ou pelo menos parcialmente automatizada, sem deparar-se com obstáculos na passagem de segmentos do texto da língua-fonte para a língua-alvo.

Sua noção de problema está diretamente ligada à de estratégia, definida como "procedimentos que os sujeitos empregam para resolver problemas tradutórios" (LÖRSCHER, 
1991, p. 99, tradução nossa ${ }^{6}$ ). Assim, em sua análise sobre as fases nas quais as estratégias são empregadas pelos tradutores (como identificação de um problema de tradução, busca por uma solução para o problema, não identificação de solução para o problema de tradução, entre outras), encontra-se a noção de problema apresentada em todas, sem exceção.

Nord (1997), por outro lado, em Translating as a Purposeful Activity, outra obra chave nos Estudos da Tradução, dedica-se ao estudo da tradução com ênfase no aspecto que a caracteriza como uma atividade ou ação humana e profissional. Embora se aproxime de abordagens funcionalistas em relação à tradução, Nord (1997) tem um ponto de vista crítico em relação a essas teorias, chamando a atenção para o fato de que tais abordagens não são descritivas. Nessa obra, a autora também relativiza os pressupostos funcionalistas mais radicais, buscando oferecer uma abordagem mais equilibrada e que não considere apenas o objetivo comunicativo como aspecto determinante dos métodos tradutórios, concepção funcionalista que considera extrema.

Em sua reflexão, Nord (1997) se concentra, entre outros fatores, no aspecto profissional da tradução e na formação e treinamento de tradutores, um dos focos das teorias funcionalistas mais recentes. Assim, pensando em treinamento de tradutores e em situações profissionais de tradução, a autora oferece uma abordagem sistemática dos problemas de tradução, mas, antes disso, destaca a diferença entre as noções de problema e dificuldade, uma contribuição extremamente valiosa para a área.

Da proposta de Nord (1997), então, depreende-se que o problema é objetivo, ou seja, é considerado sempre um problema, mesmo que o tradutor já o tenha identificado anteriormente e tenha conseguido resolvê-lo com rapidez e eficácia. A dificuldade, por outro lado, é subjetiva, já que o tradutor, ou o aprendiz de tradução, identifica uma dificuldade durante o processo tradutório em função de deficiências, que podem ser linguísticas, culturais ou referentes à competência tradutória ou, ainda, por causa de carência de documentação apropriada. A partir disso, os problemas, então, são categorizados por Nord (1997) de acordo com objetivos pedagógicos e podem ser, também, de quatro tipos distintos:

a) Pragmáticos: derivam das diferenças entre situações do texto-fonte e do textoalvo. Para Nord, esse tipo de problema está presente em toda tarefa de tradução e independe das línguas e culturas envolvidas. Podem ser identificados com a checagem de fatores extratextuais, como o emissor, o destinatário, o meio, o tempo, o local, a causa e a função textual. 
b) Culturais: derivam de elementos que caracterizam as culturas, como seus hábitos, normas e convenções, e são resultado da diferença de tais elementos entre as culturas envolvidas na tradução. Para a autora, estão presentes em quase todas as tarefas tradutórias, mas como são específicos das culturas em questão na tarefa, sua relevância depende de cada caso.

c) Linguísticos: são resultado de diferenças entre as línguas em jogo na tradução, como o vocabulário, a sintaxe e características suprassegmentais. Nord também menciona que alguns desses problemas linguísticos se referem apenas ao par de línguas em questão, como casos de cognatos, falsos amigos, circunstâncias de muitas opções de equivalência para uma unidade da língua do texto-fonte ou a inexistência de equivalência para uma unidade da língua do texto-fonte.

d) Específicos do texto: são característicos do texto-fonte em questão e podem aparecer na forma de neologismos, figuras de linguagem e jogos de palavras. Segundo Nord, esses problemas exigem que o tradutor seja criativo, já que as suas soluções não podem ser generalizadas e nem sempre se aplicam a outros casos.

Além disso, ainda em uma perspectiva pedagógica, a autora apresenta uma proposta de hierarquia funcional para os problemas de tradução, em contraponto à abordagem tradicional empregada em aulas de tradução, denominada bottom-up (literalmente, "de baixo para cima"). Essa abordagem considera a tradução como uma operação de mudança de códigos, na qual a parte mais importante é a equivalência lexical e sintática, de modo que raramente o funcionamento do texto em sua situação comunicativa é levado em consideração.

No contexto de uma tradução funcional, no entanto, Nord (1997) defende que os problemas devem ser tratados em abordagem top-down (“de cima para baixo"). Isso significa que o nível pragmático deve ser o primeiro a ser considerado, o que recai sobre a decisão da função que a tradução deve desempenhar. Em seguida, o tipo de tradução guia a decisão em relação às convenções - se o tradutor deve seguir as da cultura-fonte ou as da cultura-alvo. Finalmente, e apenas se for necessário, as diferenças entre os sistemas linguísticos entram em jogo.

Por fim, o grupo PACTE, coordenado pela professora Amparo Hurtado Albir, tem o seu interesse voltado para quatro questões fundamentais: a didática da tradução, o uso da metodologia empírica e experimental em Tradutologia, o uso de tecnologia aplicada à pesquisa em tradução e a pesquisa empírico-experimental sobre a competência tradutória. No contexto 
dessas pesquisas, o grupo desenvolveu um modelo de competência e, para sua validação, dedicou-se a analisar, entre outras, a variável "identificação e solução de problemas de tradução".

Para o grupo PACTE (2011), a competência tradutória pertence a um campo de conhecimento especializado e, portanto, isso significa que nem todos os bilíngues possuem essa competência. Trata-se de um conhecimento predominantemente procedimental e se compõe de diferentes subcompetências (bilíngue, extralinguística, instrumental, de conhecimentos sobre a tradução e estratégica) que se inter-relacionam, além de componentes psicofisiológicos. Entre os traços que caracterizam a competência, está a habilidade de resolver problemas. No modelo de competência proposto pelo grupo, essa habilidade encontra-se diretamente relacionada com a subcompetência estratégica, entendida como a subcompetência mais importante, já que é responsável por controlar o processo tradutório. Do ponto de vista cognitivo, para o grupo PACTE, a noção de problema tem grande importância, já que, para resolver um problema, diversas operações cognitivas estão envolvidas e o tradutor tem que realizar processos de tomada de decisão constantemente.

Hurtado Albir (2013), em consonância com as pesquisas que desenvolve com o grupo PACTE, considera os problemas de tradução como "dificuldades (linguísticas, extralinguísticas, etc.) de caráter objetivo que o tradutor pode enfrentar ao realizar uma tarefa de tradução" (2013, p. 286). Assim como Nord (1997), a autora destaca a diferença entre dificuldade (subjetiva) e problema (objetivo), e enfatiza que identificar uma solução automática para uma unidade não lhe tira o caráter de problema, que é objetivo e não depende do tradutor em questão. Hurtado Albir (2013) reconhece, no entanto, que estabelecer um limite entre o que é dificuldade e o que é um problema é, ainda, tarefa difícil, já que ainda se conta com uma escassez de pesquisas empíricas disponíveis sobre o tema nos Estudos da Tradução.

Considerando que há uma variedade enorme de problemas que podem afetar a compreensão e/ou a reexpressão, referindo-se a micro e macrounidades, o grupo PACTE (2011) e Hurtado Albir (2013) propõem uma categorização de problemas prototípicos que serve como base para a análise de uma das variáveis do estudo sobre a competência tradutória:

a) Problemas linguísticos: derivados de questões de léxico e morfossintaxe que podem surgir tanto na compreensão quanto na reexpressão.

b) Problemas textuais: resultado de elementos como coerência, coesão, tipo e gênero textual e estilo, que podem ocorrer também na compreensão e na reexpressão. 
c) Problemas extralinguísticos: questões culturais, enciclopédicas e relacionadas ao conhecimento do domínio.

d) Problemas de intencionalidade: referentes ao entendimento de informação contida no texto fonte. Manifestam-se na forma de intertextualidade, atos do discurso, pressuposições e implicaturas e situam-se na compreensão.

e) Problemas pragmáticos: relacionados com a tarefa da tradução e/ou o com leitor do texto-meta, afetam a reformulação.

Além disso, o grupo PACTE também entende que os problemas de tradução não são unidimensionais, já que podem apresentar características de outras categorias, e surgem quando “soluções 'automatizadas', i.e., soluções espontâneas e imediatas, não são encontradas para segmentos do texto-alvo na tradução e diferentes estratégias devem ser empregadas para resolvê-las" (PACTE, 2011, p. 328, tradução nossa ${ }^{7}$ ).

A noção de problema é considerada fundamental na reflexão tradutória do grupo PACTE e de Hurtado Albir e suas pesquisas, que consideram que saber como identificar e solucionar problemas de tradução, a partir de habilidades e estratégias, são características essenciais da competência tradutória, conjunto de conhecimentos que distingue o tradutor de outros sujeitos.

\subsubsection{Uma nova proposta de perspectiva sobre os problemas de tradução}

Com a reflexão teórica a partir dos autores recuperados, constatou-se certa contradição no espaço dedicado à noção de problema nos Estudos da Tradução. Embora se encontre pouquíssima literatura sobre o tema, a noção de problema é recorrente na discussão teórica e, principalmente, relaciona-se com as outras noções que são objeto de estudo da área. Por exemplo, em relação à equivalência, uma das noções mais estudadas e discutidas, costuma-se falar em problemas para a sua identificação. No que se refere ao conceito de unidades de tradução, destacam-se problemas encontrados para delimitá-las e problemas que elas representam para a tradução. A noção de estratégias, por sua vez, é quase dependente se consideramos que elas existem e são aplicadas justamente para solucionar problemas. O erro, finalmente, costuma ser identificado como o resultado de problemas de tradução não considerados como tal ou, por outro lado, leva a problemas que são identificados no texto traduzido.

Com base na noção geral de problema, elaborada no contexto da reflexão matemáticofilosófica, e na sua aplicação, ainda que incipiente, na área de Estudos da Tradução, propõe-se 
que o problema de tradução, embora possa ser compreendido como uma dificuldade e, portanto, como um desafio para o tradutor, pode ser visto como positivo pelas seguintes razões:

- $\quad$ no sentido pedagógico, é útil na formação de tradutores que sejam capazes de identificá-lo e solucioná-lo;

- $\quad$ é um aspecto enriquecedor das línguas naturais e das linguagens especializadas em jogo no ato tradutório, na medida em que, no processo de sua resolução, pode ser uma fonte geradora de unidades neológicas, especializadas ou não, para unidades do texto original sem equivalente consagrado;

- $\quad$ sua identificação pode demonstrar as diferenças culturais, textuais, linguísticas e extralinguísticas dos dois sistemas envolvidos na tradução;

- $\quad$ seu reconhecimento, embora objetivo, confirma a necessidade de sujeitos humanos no processo de tradução, já que sua resolução exige, em muitos casos, a subjetividade do tradutor.

Assim,em Waquil (2017), defende-se que sua existência é, por fim, não apenas importante, mas fundamental para a manutenção e evolução dos estudos sobre a tradução nos mais variados contextos.

Resumidamente, portanto, são apresentados os fatores que sintetizam a visão que se propôs em Waquil (2017) para os problemas no contexto da tradução:

a) podem configurar obstáculos para a realização de uma tarefa tradutória;

b) são constatados no processo de identificação de equivalências (entre textos ou entre unidades menores dos textos) durante a tradução;

c) podem ser linguísticos, extralinguísticos, terminológicos, textuais, de intencionalidade e pragmáticos;

d) são manifestados tanto na compreensão quanto na reexpressão, e há casos em que ocorre em ambas;

e) sua solução exige a aplicação de estratégias;

f) são elementos propositores da evolução do conhecimento da área dos Estudos da Tradução. 


\section{A análise de problemas de tradução: o caso da tradução espanhol/português de}

\section{Traducción y Traductología}

Para a realização da pesquisa apresentada em Waquil (2017), com supervisão e orientação da professora Hurtado Albir, procedeu-se a um estudo exploratório baseado na tradução do primeiro capítulo da obra Traducción y Traductología e na identificação de problemas decorrentes dessa atividade tradutória.

O primeiro capítulo selecionado para tradução, embora fosse introdutório, já apresentava questões fundamentais para a discussão desenvolvida ao longo de todo o livro. Do ponto de vista da identificação de equivalentes, introduz temas problemáticos: conceitos especializados, exemplos, figuras, citações, entre outros. Nesse primeiro capítulo, Hurtado Albir apresenta sua distinção entre tradução e Tradutologia (Estudos da Tradução), introduz a finalidade e os aspectos que caracterizam a tradução, traz definições existentes na literatura sobre a atividade e sua própria definição, com muitas citações, exemplos e figuras.

Para a identificação dos problemas ao longo da tradução, tomou-se como base a categorização proposta pelo grupo PACTE e por Hurtado Albir, composta por problemas linguísticos, textuais, extralinguísticos, de intencionalidade e pragmáticos.

Após a tradução do primeiro capítulo e a documentação de notas durante esse processo, realizadas no ambiente da ferramenta $\mathrm{OmegaT}^{8}$, procedeu-se ao preenchimento de uma ficha elaborada para a identificação, descrição e análise dos problemas identificados. Nessa ficha, a partir das notas produzidas durante a tradução, foram: compilados os segmentos nos quais se encontravam os problemas; descritos os problemas a partir das dificuldades encontradas; identificados os tipos de problema de acordo com a categorização previamente selecionada; propostas as soluções possíveis.

A seguir, apresentam-se exemplos do levantamento de dados organizados na ficha para a identificação dos problemas (WAQUIL, 2017):

Quadro 1 - Exemplos da ficha do estudo exploratório

\begin{tabular}{|l|l|l|l|}
\hline \multicolumn{1}{|c|}{$\begin{array}{c}\text { Segmento do } \\
\text { texto }\end{array}$} & $\begin{array}{c}\text { Descrição da(s) } \\
\text { dificuldade(s) } \\
\text { encontrada(s) }\end{array}$ & \multicolumn{1}{|c|}{$\begin{array}{c}\text { Tipo(s) de } \\
\text { problema }\end{array}$} & \multicolumn{1}{c|}{$\begin{array}{c}\text { Solução(es) } \\
\text { possível(eis) }\end{array}$} \\
\hline $\begin{array}{l}\text { Del mismo modo, } \\
\text { cuando alguien } \\
\text { estornuda en } \\
\text { nuestra presencia, } \\
\text { en español se dice } \\
\text { Jesús!; en catalán }\end{array}$ & $\begin{array}{l}\text { Introduzir exemplo } \\
\text { na língua de } \\
\text { chegada do } \\
\text { público-alvo }\end{array}$ & $\begin{array}{l}\text { Pragmático e } \\
\text { extralinguístico } \\
\text { (enciclopédico) }\end{array}$ & $\begin{array}{l}\text { Saúde!/ } \\
\text { Deus te abençoe! }\end{array}$ \\
\hline
\end{tabular}




\begin{tabular}{|c|c|c|c|}
\hline $\begin{array}{l}\text { Salut!; en francés } \\
\text { A vos souhaits!; } \\
\text { en inglés Bless } \\
\text { you!; etc. }\end{array}$ & & & \\
\hline $\begin{array}{l}\text { El encargo de } \\
\text { traducción puede } \\
\text { tener diversas } \\
\text { finalidades }\end{array}$ & $\begin{array}{l}\text { Identificar unidade } \\
\text { terminológica } \\
\text { equivalente entre } \\
\text { possíveis variantes } \\
\text { na língua de } \\
\text { chegada }\end{array}$ & $\begin{array}{l}\text { Extralinguístico } \\
\text { (terminológico) }\end{array}$ & $\begin{array}{l}\text { A encomenda/ } \\
\text { a solicitação/ } \\
\text { o encargo/ } \\
\text { o trabalho de } \\
\text { tradução }\end{array}$ \\
\hline $\begin{array}{l}{[\ldots] \text { son elementos }} \\
\text { que rigen la } \\
\text { traducción y } \\
\text { también la } \\
\text { reflexión en torno } \\
\text { a ella. }\end{array}$ & $\begin{array}{l}\text { Identificar } \\
\text { colocação } \\
\text { equivalente }\end{array}$ & Linguístico & $\begin{array}{l}\text { Determinam/ } \\
\text { guiam a tradução }\end{array}$ \\
\hline $\begin{array}{l}\text { y que, como todo } \\
\text { conocimiento } \\
\text { operativo, se } \\
\text { adquiere } \\
\text { fundamentalmente } \\
\text { por la práctica (cfr. } \\
\text { infra VI.2. «La } \\
\text { competencia } \\
\text { traductora»). }\end{array}$ & $\begin{array}{l}\text { Normatizar } \\
\text { remissão textual }\end{array}$ & Textual & $\begin{array}{l}\text { Ver/ } \\
\text { conferir }\end{array}$ \\
\hline
\end{tabular}

Fonte: Waquil, 2017.

Após o preenchimento da ficha, procedemos à análise dos resultados obtidos, observando cada um dos campos e as informações neles contidas. Analisando os segmentos problemáticos selecionados, chegamos ao seguinte resultado quantitativo de ocorrências de problemas no estudo exploratório:

Quadro 2-Análise quantitativa dos problemas

\begin{tabular}{|c|c|c|}
\hline \multicolumn{2}{|c|}{ TIPO DE PROBLEMA ENCONTRADO } & $\begin{array}{c}\text { NÚMERO DE } \\
\text { OCORRÊNCIAS NO } \\
\text { ESTUDO } \\
\text { EXPLORATÓRIO }\end{array}$ \\
\hline \multirow[t]{2}{*}{ Problemas linguísticos } & Compreensão & 0 \\
\hline & Reexpressão & 10 \\
\hline \multicolumn{2}{|c|}{ Problemas extralinguísticos } & 61 \\
\hline \multicolumn{2}{|l|}{ Problemas textuais } & 04 \\
\hline \multicolumn{2}{|c|}{ Problemas de intencionalidade } & 01 \\
\hline \multicolumn{2}{|l|}{ Problemas pragmáticos } & 23 \\
\hline
\end{tabular}

Elaboração: Marina Leivas Waquil 
É importante deixar claro, no entanto, que os problemas foram compilados com base no modelo type, em oposição a tokens. Isto é, embora um mesmo problema em relação a alguma unidade fosse identificado ao longo do capítulo inúmeras vezes, na ficha e na análise quantitativa foi adicionado apenas uma vez. Um exemplo é a unidade terminológica encargo de traducción, que aparece seis vezes no primeiro capítulo, mas em todas as ocorrências apresenta a mesma estrutura (com variação no número ou com adição do artigo la - encargo de la traducción) e se refere ao mesmo conceito.

A partir dessa análise quantitativa, então, observou-se que, com maior expressividade numérica, destacaram-se como elementos representativos geradores de problema para a tradução os extralinguísticos, que corresponderam a quase $63 \%$ dos problemas identificados. Entre os 61 problemas extralinguísticos identificados, 56 (quase 92\%) derivavam de questão terminológica, isto é, referiam-se a questões referentes ao domínio especializado que caracteriza o texto. Por essa razão, em Waquil (2017), tomou-se como foco os problemas terminológicos de tradução.

No entanto, cabe destacar com mais detalhe o processo de identificação desses problemas no processo de tradução entre o espanhol e o português. Isso se deve, principalmente, em função de que a categorização proposta desses problemas incluiu unidades com pouco ou nenhum grau de opacidade semântica (como "receptor", por exemplo, que tem a mesma grafia em ambas as línguas), o que poderia levar a crer que não são unidades problemáticas. A opção de identificar essas unidades como problemas se justifica, antes de tudo, pelo fato de que entendemos que os problemas são constatações objetivas (embora com certo grau de subjetividade inerente), que independem do nível de conhecimento e/ou competência do tradutor. Por isso, e principalmente no contexto espanhol/português, embora alguns termos possam parecer simples do ponto de vista formal e/ou conceitual, devem ser entendidos como problemas, tendo em vista que são objetivos e independem da subjetividade do tradutor.

Além disso, propõe-se que a terminologia, característica intrínseca dos textos especializados e que pode estar presente em textos não especializados, sempre exige que o tradutor busque e selecione equivalentes de uma forma que não é exatamente deliberada. Exige adequação à terminologia utilizada na outra língua e, também, correção em relação aos conceitos que os termos representam - com confirmação terminológica ou, em certos casos, proposta neológica.

Corroborando o caráter de problema das questões terminológicas identificadas, também se entende que casos aparentemente não tão óbvios de problemas terminológicos também 
podem configurar-se como problemas. Isso pode dever-se a questões de variação denominativa (para o já mencionado termo receptor, por exemplo, temos como variantes destinatário, público, entre outros), o que representa uma dificuldade e, sem dúvida, um problema que o tradutor deve enfrentar.

Finalmente, também optou-se por identificar como problema as unidades e estruturas terminológicas devido ao fato de que elas impõem, mesmo ao tradutor mais experiente, uma especificidade para a reexpressão. Ainda que tenha competência cognitiva suficiente para propor o equivalente para o termo, o tradutor busca confirmação terminológica, porque, ao representar um conceito de uma linguagem especializada, depara-se com, em seu fazer, com a necessidade de precisão e adequação para a tradução que propõe.

A partir dessa pesquisa, dos resultados da revisão teórica e da análise do processo tradutório realizado, decidiu-se revisar e propor uma nova categorização de problemas de tradução que contemplasse a terminologia como um fator fundamental para a identificação de equivalentes. Dessa forma, amplia-se seu caráter de apenas elemento extralinguístico e destacase sua relevância para a resolução de problemas na tradução de textos especializados. Assim,

30 tomando como base o estudo das dificuldades ${ }^{9}$ levantadas pelo grupo PACTE para estabelecer uma categorização que guiasse a realização de nosso estudo, a seguinte categorização foi proposta (WAQUIL, 2017):

Quadro 3-Categorização de problemas

\begin{tabular}{|l|l|}
\hline \multicolumn{1}{|c|}{ PROBLEMA } & \multicolumn{1}{|c|}{ DEFINIÇÃO/EXPLICAÇÃO } \\
\hline Problemas linguísticos & $\begin{array}{l}\text { Derivam de dificuldades de compreensão e/ou } \\
\text { reexpressão do tradutor em relação a questões } \\
\text { linguísticas (léxico e morfossintáticas). }\end{array}$ \\
\hline Problemas extralinguísticos & $\begin{array}{l}\text { Derivam de dificuldades de compreensão e/ou } \\
\text { reexpressão que o tradutor enfrenta relacionadas a } \\
\text { aspectos enciclopédicos e culturais referentes ao par } \\
\text { de línguas em questão na tradução. }\end{array}$ \\
\hline Problemas terminológicos & $\begin{array}{l}\text { Derivam de dificuldades de compreensão e/ou } \\
\text { reexpressão que o tradutor identifica com relação a } \\
\text { um tipo de conhecimento extralinguístico que é } \\
\text { temático, composto por unidades e estruturas de } \\
\text { linguagens especializadas que, por sua vez, } \\
\text { caracterizam a comunicação de todos os campos } \\
\text { especializados do conhecimento humano. }\end{array}$ \\
\hline Problemas textuais & $\begin{array}{l}\text { Derivam de dificuldades de compreensão e/ou } \\
\text { reexpressão que surgem quando o tradutor se depara } \\
\text { com diferenças de funcionamento textual entre as } \\
\text { duas línguas em jogo na tradução (como, por }\end{array}$ \\
\hline
\end{tabular}




\begin{tabular}{|l|l|}
\hline \multirow{5}{*}{ Problemas de intencionalidade } & $\begin{array}{l}\text { exemplo, coesão, coerência, tipos textuais, gêneros, } \\
\text { estilo, etc.). }\end{array}$ \\
\hline & $\begin{array}{l}\text { Derivam de dificuldades de compreensão que o } \\
\text { tradutor encontra com relação ao entendimento de } \\
\text { informação contida no texto da língua-fonte, em } \\
\text { função de elementos como, por exemplo, a intenção } \\
\text { comunicativa, a intertextualidade, pressuposições, } \\
\text { metáforas, entre outros. }\end{array}$ \\
\hline Problemas pragmáticos & $\begin{array}{l}\text { Derivam de dificuldades de reexpressão que surgem } \\
\text { para o tradutor no que se refere a elementos como } \\
\text { as características e as necessidades do destinatário } \\
\text { da tradução, sua finalidade, o contexto em que se } \\
\text { desenvolve e a solicitação do trabalho de tradução } \\
\text { em si, entre outros. }\end{array}$ \\
\hline
\end{tabular}

Fonte: Waquil, 2017.

Ao analisar especificamente os problemas terminológicos na busca por equivalentes para as unidades terminológicas envolvidas, foram encontradas quatro categorias de problemas específicos na tradução de Traducción y Traductología para o português:

1) Unidades terminológicas sem equivalente consagrado na língua de chegada: quando não foi possível identificar equivalente consagrado na linguagem especializada em português após busca no corpus compilado para tal fim e em sites e recursos confiáveis da área em questão. Exemplo: traducción a la francesa (termo referente à tradução que adapta as manifestações estrangeiras, no contexto do que o escritor Goethe denomina como época parodística da tradução alemã).

2) Unidades terminológicas neológicas: identificação de unidade terminológica neológica que ainda não está consagrada na linguagem especializada, que esteja em processo de consagração ou que apenas recentemente tenha sido consagrada pelo uso. Exemplo: equivalente acuñado (técnica de tradução proposta por Hurtado Albir).

3) Presença de unidades terminológicas de outras áreas (interdisciplinaridade): recorrente no contexto de textos de ciências modernas, que interagem e desenvolvem seu conhecimento também a partir de sua interface com outras áreas. É identificado a partir da necessidade de lidar, na tradução, com a transmissão de outro tipo de conhecimento especializado, buscando diferentes fontes e recursos para a identificação e/ou confirmação de equivalente. Exemplo: acto de habla (representativos, expresivos, veredictivos, directivos, obligativos, declarativos) - unidades derivadas da Linguística e da Filosofia da Linguagem.

4) Unidades terminológicas com variação denominativa: identificado quando são constatadas variantes da unidade terminológica para a qual se busca um equivalente na língua 
de chegada, com a presença, ou não, de traços semânticos diferenciais entre as unidades variantes. Exemplo: metáfrasis/traducción palabra por palabraltraducción verso por verso.

\section{Considerações finais}

A partir desta discussão e com base em Waquil (2017), defende-se que a noção de problema nos Estudos da Tradução deve: 1) ter um espaço garantido nas reflexões teóricas e empíricas, tanto em sua vertente teórica quanto na prática e na pedagógica, 2) e que seja proposta, analisada e considerada a partir de uma perspectiva que toma o problema como elemento que possibilita e propõe a produção de conhecimento e de resultados para as mais diversas áreas do saber humano. Nesse sentido, a partir da presença extensa de problemas terminológicos identificados na tradução do espanhol para o português de Traducción y Traductología, entende-se que o enfrentamento desses problemas contribui, também, para o desenvolvimento da linguagem especializada em questão. Além disso, oferece subsídios para as línguas em jogo na tradução, já que leva à necessidade de soluções que enriquecem essas áreas.

No processo realizado nessa pesquisa, cabe destacar a grande dificuldade em encontrar reflexões e categorizações centradas na noção de problema na tradução, o que, se por um lado foi um desafio, também foi um estímulo para a realização do trabalho com este foco e demonstra a necessidade de que se siga investindo nessa discussão. Devido a essa carência na análise da literatura e refletindo a respeito de uma noção sobre a qual há pouquíssimo consenso na literatura, tomou-se como base alguns pressupostos dos autores revisados e acrescentou-se uma contribuição teórica específica à noção, propondo "problema terminológico" como uma categoria particular de problema de tradução. Embora as categorizações analisadas mencionassem a influência de aspectos "temáticos” na identificação de problemas na tradução, ainda não se tinha dado o espaço adequado que a terminologia merece e representa para a problemática da identificação de equivalentes na tradução de textos especializados.

Finalmente, destaca-se o intuito de desmistificar a ideia de problema na tradução, de modo que lhe possamos tirar o caráter negativo, dando-lhe, sim, o valor positivo que os problemas têm na evolução das ciências, ao colaborarem no desenvolvimento do conhecimento e na proposição de novas perspectivas. 


\section{REFERÊNCIAS BIBLIOGRÁFICAS}

BERGSON, Henri. OEuvres. Paris : PUF, 1959.

DELEUZE, Gilles. Bergsonismo. Traduzido por: Luiz B. L. Orlandi. São Paulo: Editora 34, 2012.

DELEUZE, Gilles. Le Bergsonisme. Paris: PUF, 1966.

ECO, Umberto. Quase a mesma coisa: experiências de tradução. São Paulo: Record, 2007.

FRANCO, Javier. Who's who and what's what in Translation Studies: a preliminary approach. In: FRANCO, Javier. Tracks and Treks in Translation Studies, Amsterdam: John Benjamins Publishing Company, 2010. p. 7-28.

HURTADO ALBIR, Amparo. Traducción y traductología: introducción a la traductología. Madrid: Ediciones Cátedra, 2013.

LÖRSCHER, Wolfgang. Translation performance, translation process and translation strategies. Tübingen: Gunter Narr Verlang, 1991.

MOUNIN, Georges. Les Problèmes théoriques de la traduction. Paris: Gallimard, 1963.

NORD, Christiane. Translating as a Purposeful Activity. In: NORD, Christiane.

Functionalist Approaches Explained. Manchester: St. Jerome, 1997.

PACTE. (BEEBY, A.; FERNÁNDEZ, M.; FOX, O.; HURTADO ALBIR, A.; KUZNIK, A.; NEUNZIG, W.; RODRÍGUEZ-INÉS, P.; ROMERO, L.; WIMMER, S. Investigadora principal: HURTADO ALBIR, A.). Results of the Validation of the PACTE Translation Competence Model: Translation Problems and Translation Competence. In: ALVSTADA, Cecilia; HILD, Adelina; TISELIUS, Elisabet (Ed.) Methods and Strategies of Process Research: Integrative Approaches in Translation Studies. Amsterdam: John Benjamins, 2011. p. 317-343.

ROQUE, Tatiana. Sobre a noção de problema. Lugar comum, n. 23-24, p. 135-146, 2008.

WAQUIL, Marina. Traduzindo Traducción y Traductología: problemas terminológicos de tradução. Tese (Doutorado em Letras) - Programa de Pós-Graduação em Letras, Universidade Federal do Rio Grande do Sul, Rio Grande do Sul, 2017. Disponível em: https://lume.ufrgs.br/bitstream/handle/10183/166273/001027759.pdf?sequence=1\&isAllowed =y Acesso em: 24 set. 2019.

\footnotetext{
* Marina Leivas WAQUIL - Doutora (2017) e Mestre (2013) em Letras pela Universidade Federal do Rio Grande do Sul. Bacharel em Letras Português/Espanhol com habilitação em tradução (2010) pela mesma instituição. Tradutora pública e intérprete comercial concursada pela Junta Comercial do Rio Grande do Sul. Porto Alegre, Rio Grande do Sul, Brasil.

Currículo acadêmico: http://lattes.cnpq.br/6151947734463082

ORCID: https://orcid.org/0000-0003-1773-5380

E-mail: marinawaquil@gmail.com
} 
${ }^{1}$ BITRA (Bibliografia de Interpretação e Tradução) é uma base de dados de referências de bibliografia das áreas de Tradução e Interpretação. De acordo com os dados de Franco (2010), BITRA é multilíngue e internacional, já que é composta por trabalhos de todo o mundo e apresenta uma interface que pode ser acessada em 12 línguas: catalão, holandês, inglês, francês, galego, alemão, italiano, japonês, coreano, português, romeno e espanhol; oferece, além de informação bibliográfica, resumos, tabelas e quadros; é interativa, já que seus usuários podem colaborar com a base oferecendo novas entradas para submissão, além de poder modificá-las; é atualizada mensalmente; é bibliométrica, estudando desde 2010 o impacto nos estudos sobre tradução das obras que inclui; e é, por fim, aberta e está disponível para qualquer um no endereço eletrônico: http://aplicacionesua.cpd.ua.es/tra_int/usu/buscar.asp?idioma=es. Acesso em: 28 set. 2019.

2 O Grupo PACTE (Processo de Aquisição da Competência Tradutória e Avaliação), fundado em 1997, na Universidade Autônoma de Barcelona, Espanha, é coordenado pela professora Amparo Hurtado Albir.

${ }^{3}$ No original : "un secteur inexploré, voire ignoré [...] se trouvant à l'intersection de plusieurs sciences".

${ }^{4}$ No original: "they function as both the starting-point of and the reason for the use of translation strategies. As a consequence, translation strategies only occur when translation problems exist".

${ }^{5}$ No original: "prevent or delay, or which only partially or inadequately allow the transformation of SL text segments into TL".

${ }^{6}$ No original: "procedures which the subjects employ in order to solve translation problems".

${ }^{7}$ No original: "'automatized' solutions, i.e. spontaneous and immediate solutions, are not found for source-text segments in translation and different strategies are then put into effect to solve then".

${ }^{8}$ Para a realização do estudo exploratório, contou-se com o ambiente proporcionado pela ferramenta de tradução OmegaT, que permitiu o mapeamento de informações relevantes para a pesquisa. O OmegaT foi criado em 2002, por Keith Godfrey, como uma ferramenta de memória de tradução livre, gratuita e programada em Java. Foi elaborado com foco em um público de tradutores profissionais e apresenta diversos elementos que podem facilitar e organizar a atividade de tradução. Diferentemente de ferramentas de tradução automática, o OmegaT é uma ferramenta de apoio à tradução, o que faz oferecendo diversos recursos aos usuários, como organização de glossários, segmentação textual, a criação de notas e comentários ao texto, a inserção de correspondências entre segmentos, entre outros.

${ }^{9}$ No artigo mencionado, o grupo PACTE não entra na questão da diferenciação e do limite entre "dificuldade" e "problema". O termo "dificuldade" é introduzido no contexto da análise das respostas dadas por tradutores a um questionário sobre problemas de tradução encontrados em um experimento que o grupo realizou. Entende-se que ambas as noções estão intimamente correlacionadas na visão do grupo e que, para fins de categorização de problemas, a tipologia de dificuldades pode acrescentar à de problemas. 